\title{
Germination of Sweet Sorghum Seeds in Different Water Potentials
}

\section{Rodrigo Kelson Silva Rezende, Tathiana Elisa Masetto, Guilherme Cardoso Oba, Maílson Vieira Jesus}

Faculty of Agrarian Sciences, Federal University of Grande Dourados, Dourados, Brazil

Email: rkelson@ufgd.edu.br

How to cite this paper: Rezende, R.K.S., Masetto, T.E., Oba, G.C. and Jesus, M.V. (2017) Germination of Sweet Sorghum Seeds in Different Water Potentials. American Journal of Plant Sciences, 8, 3062-3072. https://doi.org/10.4236/ajps.2017.812206

Received: October 3, 2017

Accepted: November 12, 2017

Published: November 15, 2017

Copyright $\odot 2017$ by authors and Scientific Research Publishing Inc. This work is licensed under the Creative Commons Attribution International License (CC BY 4.0).

http://creativecommons.org/licenses/by/4.0/

\begin{abstract}
The implantation of sweet sorghum has been shown as viable alternative in crop rotation in sugar cane plantation reform areas. The seed environment in the field is complex and several factors, such as different genotypes and osmotic stress, can negatively influence the seeds water uptake and, therefore, the sequence of germination events can be compromised. In this context, the objective of this study was to evaluate the different physiological responses of sweet sorghum seeds (Sorghum bicolor (L.) Moench) belonging to the hybrids CV 007 and CV 147 and cultivar BRS 506 when submitted to substrates with different water potentials $(-0.1,-0.2,-0.3,-0.4$, and $-0.5 \mathrm{MPa})$ using solutions of polyethylene glycol (PEG 6000). The seeds remained in Biochemical Oxygen Demand-type germination chambers, under constant white light and the temperature of $25^{\circ} \mathrm{C}$ for $14 \mathrm{~h}$ in the high temperature and $10 \mathrm{~h}$ in the low temperature. The moisture of the substrates was regularly monitored. The physiological potential of the genotypes was evaluated using the following characteristics: first count, germination, germination speed index (GSI), root length, and fresh and dry weights of seedlings. In general, germination and early growth of seedlings were negatively affected by the reduction of water potentials below $-0.1 \mathrm{MPa}$, which was also damaging to the GSI of the seeds. Germination and growth of seedlings of the hybrids CV 007 and CV 147 and of the cultivar BRS 506 were affected by reduced water potentials starting at $-0.1 \mathrm{MPa}$. The seeds of hybrid CV 147 were more tolerant to simulated water stress with PEG 6000 than those of hybrid CV 007 and cultivar BRS 506.
\end{abstract}

\section{Keywords}

Sorghum bicolor, Polyethylene Glycol, Seedlings Growth

\section{Introduction}

Sweet sorghum (Sorghum bicolor (L.) Moench) is a plant native to the African 
continent and is one of the three cultures with the greatest potential for renewable energy production, along with sugarcane and sugar beet. The introduction of sweet sorghum in the reform areas has resulted in an increase in the annual ethanol production by approximately $12 \%$ because the sorghum harvest could be extended by 30 days. Moreover, the use of sorghum has been proven beneficial during the off-season (December to late March), and therefore, its propagation was not intended to compete against sugarcane, but to serve as a viable alternative in the crop rotation in sugar plantation reform areas. Sorghum provides the adequate amount of bagasse sufficient to generate steam for industrial activities, besides being compatible to a fully mechanized culture. However, it markedly differs from sugarcane in terms of the growth cycle, the latter being much shorter, between 120 to 130 days [1] [2], allowing the harvest of sugarcane during a more favorable period, preventing losses in the quality of the material, and allowing ethanol production during periods of low inventories [3].

Similar to sugarcane, sweet sorghum stores sugars in its stems [2], produces grains with nutritional characteristics similar to those of corn, which can be used in animal feed, and supplies sufficient amounts of bagasse for co-generation of electricity and energy supply for industrial processes. The amount of total sugars $(10 \%-14 \%)$ and fiber $(11 \%-16 \%)$ is very similar to those from sugarcane [3] [4]. Its juice can be used for the production of excellent quality rum in regions with no sorghum cultivation, such as the Brazilian northeast, thus, becoming a means to broaden the sources of income.

In Brazil, the areas with the highest suitability for the cultivation of sweet sorghum are concentrated in São Paulo, northwestern Paraná, eastern Mato Grosso do Sul, and southwestern Goiás, whereas most areas with intermediate suitability are in Minas Gerais and Goiás [5]. Sweet sorghum is efficient in the production of renewable energy, but this culture can be affected by biotic and abiotic stresses specific to each region [6]. Reference [7] has reported that sweet sorghum can be used as raw material in ethanol production under environmental conditions of warm and dry weathers because this culture is more resistant to drought than sugarcane and corn. It is easy to plant sorghum in dry soil, unlike sugarcane, which needs moisture and highly fertile soils [8].

According to [9], water is critical for the activation of metabolic processes in the seed, culminating in its germination. The environment of the seed in the field is complex and may fluctuate over time. Furthermore, the depth of sowing, climate, and soil conditions also determine the speed at which seed germination and emergence occur. However, the effects of these factors on water transport through the imbibition of seeds in unsaturated substrates have remained elusive [10]. Thus, the existence of critical levels of water potential, particularly at the start of imbibition, negatively influences water absorption in seeds, and therefore, the sequence of germination events may be compromised.

Under osmotic stress simulated with polyethylene glycol (PEG), physiological responses can vary with species [11], as was also observed in different genotypes 
(i.e., the genetic potential can influence the tolerance of seeds in relation to water stress conditions of the substrate). On the basis of the economic potential of the culture and lack of information on the effects of water stress on the germination and growth of seedlings, this study aimed to evaluate the physiological responses of sweet sorghum seeds when cultured in substrates with different degrees of water availability.

\section{Material and Methods}

The study was conducted at the Seed Laboratory of the Faculty of Agricultural Sciences, Federal University of Grande Dourados, using two seed lots of sweet sorghum hybrids CV 007 and CV 147 and a seed lot of the cultivar BRS 506. Initially, the moisture content of the seeds was determined using the oven method at $103^{\circ} \mathrm{C} \pm 2^{\circ} \mathrm{C}$ for $24 \mathrm{~h}$, using four replicates, following the Rules for Seed Testing [12]. The results were calculated based on the weight of the wet seeds and were expressed in percentages.

To assess the effect of the different potentials of the substrate in seed germination, water solutions of polyethylene glycol (PEG 6000) were used, with potentials of $-0.1,-0.2,-0.3,-0.4$, and $-0.5 \mathrm{MPa}$. The corresponding amount of PEG 6000 was calculated based on the equation proposed by [13], as follows: $\psi \mathrm{os}=$ $-\left(1.18 \times 10^{-2}\right) \mathrm{C}-\left(1.18 \times 10^{-4}\right) \mathrm{C}^{2}+\left(2.67 \times 10^{-4}\right) \mathrm{CT}+\left(8.39 \times 10^{-7}\right) \mathrm{C}^{2} \mathrm{~T}$, where \%os $=$ osmotic potential (bar); C = concentration (grams of PEG 6000/kg of distilled water); and $\mathrm{T}=$ temperature $\left({ }^{\circ} \mathrm{C}\right)$, which was set at $25^{\circ} \mathrm{C}$. Thus, to obtain water potentials of $-0.1,-0.2,-0.3,-0.4$, and $-0.5 \mathrm{MPa}$, the aqueous solutions were composed respectively of 80,120,150,165, and $190 \mathrm{~g}$ of PEG 6000 per kg of distilled water.

The seeds were placed in gerbox-type plastic boxes lined with two sheets of germitest paper, moistened with $10 \mathrm{~mL}$ of aqueous solutions of PEG. The seeds of each genotype that were sown on paper moistened with distilled water at a ratio of 2.5 times the weight of the dry paper constituted the control $(0.0 \mathrm{MPa})$. The gerboxes with seeds remained inside biochemical oxygen demand (BOD)-type germination chambers, with constant white light at $25^{\circ} \mathrm{C}$, according to [12]. The moisture of the substrates was monitored regularly.

The effect of PEG-induced water stress on germination of sweet sorghum seeds was evaluated using the following characteristics: Course of cumulative germination (CCG), for which the cumulative germination was accounted for. It was evaluated through the seeds showed approximately $2 \mathrm{~mm}$ radicle length and/or until the germination was stabilized. For each time, the maximum final germination percentage was calculated. First count, which was performed with the germination test according to the recommendations of [12], consisted of the percentages of normal seedlings on the fourth day after sowing. Germination, which was evaluated on the tenth day after sowing, was the time at which the seeds produced normal seedlings and were considered to have germinated [12].

Germination speed index (GSI) was obtained by recording the number of 
germinated seeds daily, and calculations were performed according to [14]. Root length was measured to evaluate the effect of water stress on the growth of seedlings; 15 seeds were placed in the upper third of the roll of the germitest paper and maintained under the same conditions previously mentioned. Ten days after sowing, the average length of the primary root of seedlings was measured using a ruler graduated in millimeters and the results were expressed in centimeters. Root fresh weight was obtained by gravimetry from the roots of the same seedlings that were previously measured for their lengths, and the results were expressed in grams. Root dry weight, which was measured after obtaining the root fresh weight, was obtained by keeping the plant material in a forced ventilation oven at a temperature of $65^{\circ} \mathrm{C} \pm 2^{\circ} \mathrm{C}$ for $48 \mathrm{~h}$, and the dry weight was determined by weighing the samples on an analytical scale and the results were expressed in grams.

The tests were conducted in a completely randomized design using four replicates of 50 seeds for each treatment, in a factorial arrangement of $3 \times 5$ (genotypes and water potentials). The CCG with water potentials, separated for genotypes, was described by a non-linear regression [15]. The statistical analyzes of the other tests were performed using the means obtained, which were submitted to ANOVA and when significant values were obtained, they were subjected to regression analysis at $5 \%$ probability by using the SISVAR statistical program [16].

\section{Results and Discussion}

The moisture content of the hybrid seed lots CV 007 and CV 147 was $10.4 \%$ and $10.1 \%$, respectively, and $10.3 \%$ for the cultivar BRS 506. About the maximum percentage of germination, the hybrid CV 147 obtained the highest result with $95.6 \%$ of germination, followed by the cultivar BRS 506, with $92.9 \%$. The hybrid CV 007 showed the lowest result (83.6\%). The time courses of cumulative germination at different water potentials for each cultivar are illustrated in Figure 1.

In general, it was observed the water stress caused the inhibition and delay the seeds germination progress for all of the three genotypes. The seeds from hybrid CV 007 were negatively affected by the water potentials, which probably implied the lowest percentage of germination. However, it showed the higher speed to reach $50 \%$ of the total germination than the cultivar BRS 506, which may indicate a higher rate of recovery. There were no differences between the total percentages of germination at each level of water potential for cultivar BRS 506, indicating a lower deleterious effect of the water potentials for this genotype. The CV 147 hybrid did not differ in relation to the total germinated seeds of the cultivar and did not differ about the speed to reach the half of the final germination. The hybrid CV 147 on control treatment reached 50\% of total germination in 120 hours, the faster in comparison to the others, which indicates a higher water uptake intrinsic to the genotype. It was observed that the seeds submitted at -0.4 

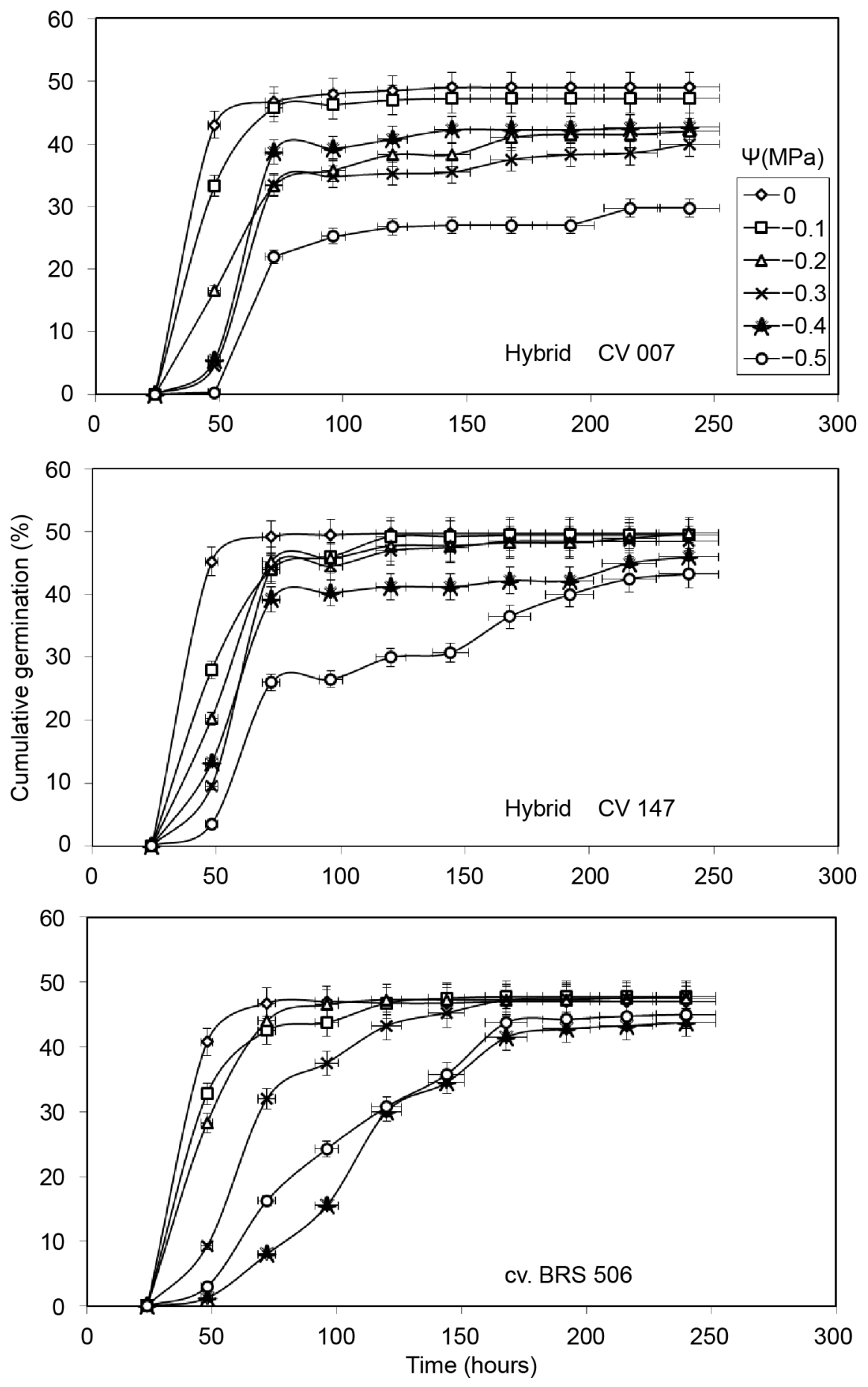

Figure 1. Cumulative germination time courses at different water potentials $(\Psi)$ for seeds of sweet sorghum hybrid CV 007, hybrid CV 147 and cultivar (cv.) BRS 506.

$\mathrm{MPa}$ and $-0.5 \mathrm{MPa}$, both after 240 hours showed decrease in the total germination of $7.5 \%$ and $13 \%$ in comparison to the control treatment, respectively. The hybrid CV 007 at $-0.2 \mathrm{MPa}$ reduced more $10 \%$ the total germination reaching half percentage only after 240 hours. The seeds submitted at $-0.5 \mathrm{MPa}$ showed $38.5 \%$ of decline in the final germination in contrast to that one submitted at 0.0 
MPa. The cultivar BRS 506, maintained its total germination average, but at 0.0 $\mathrm{MPa}$ and $-0.1 \mathrm{MPa}$ spent 168 hours to reach the half of the germination, since the time at the other treatments was 240 hours.

To highlight the differences that have occurred between different genotypes submitted to the water potentials, the reference [17] studying seeds of sweet sorghum (cv. Roce), did not verify differences in the total germination percentage at $-0.86 \mathrm{MPa}$, for seeds submitted at the temperature of $25^{\circ} \mathrm{C}$. However, there was $50 \%$ decrease in seeds germination at the same potential, but at $15^{\circ} \mathrm{C}$. In the more recent work [18], when comparing unprimed and osmoprimed seeds of cultivars Keller and the local Makueni, they found that the local Makueni exhibited a greater sensitivity to PEG-induced water stress, since the seeds germination were affected at higher levels of water stress at the same conditions as the other cultivar. In addition, both cultivars showed the decrease $30 \%$ in the seeds germination at $-0.1 \mathrm{MPa}$ and at $15^{\circ} \mathrm{C}$, after 288 hours of imbibition.

The first count results are shown in Figure 2(a), in which a significant interaction was observed between the water potentials and the genotypes assessed, except for cultivar BRS 506, which was not affected by reduced water potential during germination. Reference [19] reported that sorghum BRS 506 is recognized for its highest average yield, predictability of behavior, and adaptation to favorable environments. However, for the two lots of hybrid seeds, a linear decrease in the first count at germination was observed as the water availability decreased.

Similar results were observed for seed germination (Figure 2(b)), and no significant influence of water stress was observed for the cultivar BRS 506; however, a negative effect on the germination of hybrid seeds CV 007 and CV 147 was observed when low water potential was introduced (Figure 2(b)). For hybrid CV 147, regardless of the water availability, the germination percentage remained above 86\%. On the other hand, hybrid CV 007 presented a $57 \%$ germination percentage at a water potential of $-0.5 \mathrm{MPa}$, indicating a more sensitive behavior than that by the other evaluated lots. The influence of genetic potential on germination and growth of sorghum seedlings under conditions of reduced water availability was also observed by [20], who reported that the germination of feed sorghum CSF 18 seeds (water deficit sensitive) and CSF 20 (water deficit tolerant) varied according to the osmotic potential of the substrate solution $(-0.2,-0.4$, and $-0.8 \mathrm{MPa})$. Reference [21] who studied water stress simulated with PEG in sorghum seeds of the cultivar EA-166, observed an increase in the germination percentage as the osmotic concentration of the solution decreased, reaching values of $93 \%, 94 \%$, and $96 \%$ at $-1.2,-0.6$, and $0.0 \mathrm{MPa}$ potentials, respectively, implying that imbibition in pure water was more favorable for obtaining higher germination percentages.

Although bioenergetic crops are being grown in fallow areas and/or during autumn/winter, especially in the center-south of the Brazil, when there is 
(a)

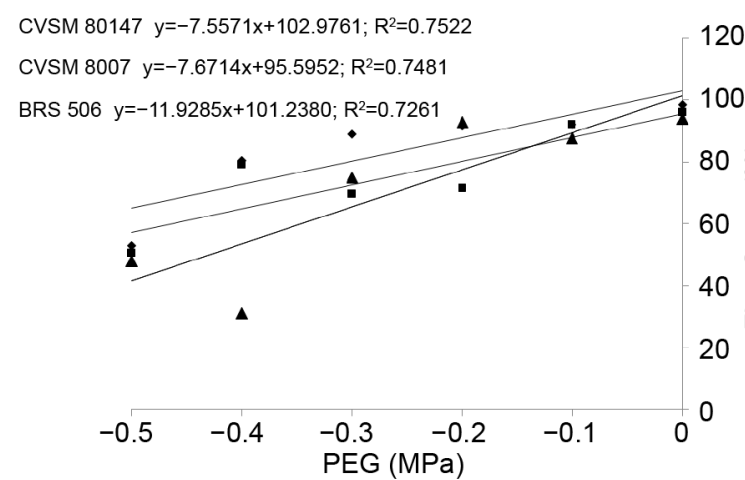

(c)

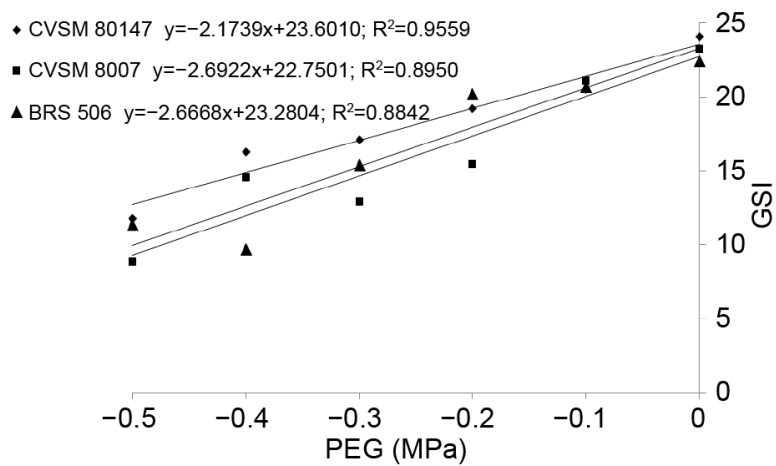

(e)

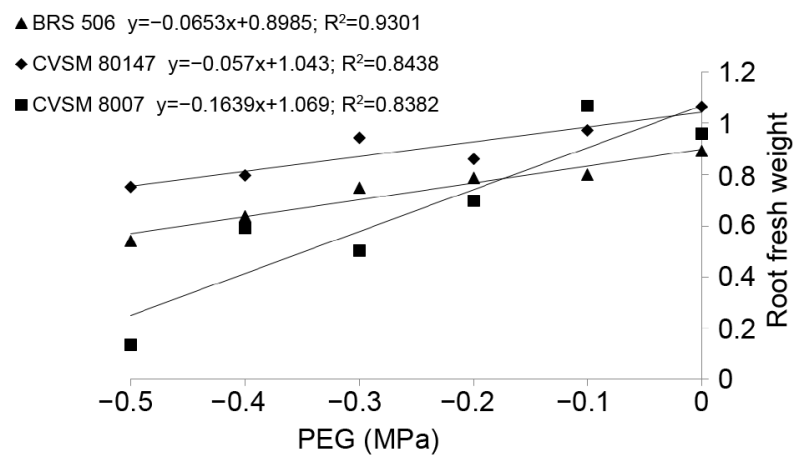

(b)

(d)
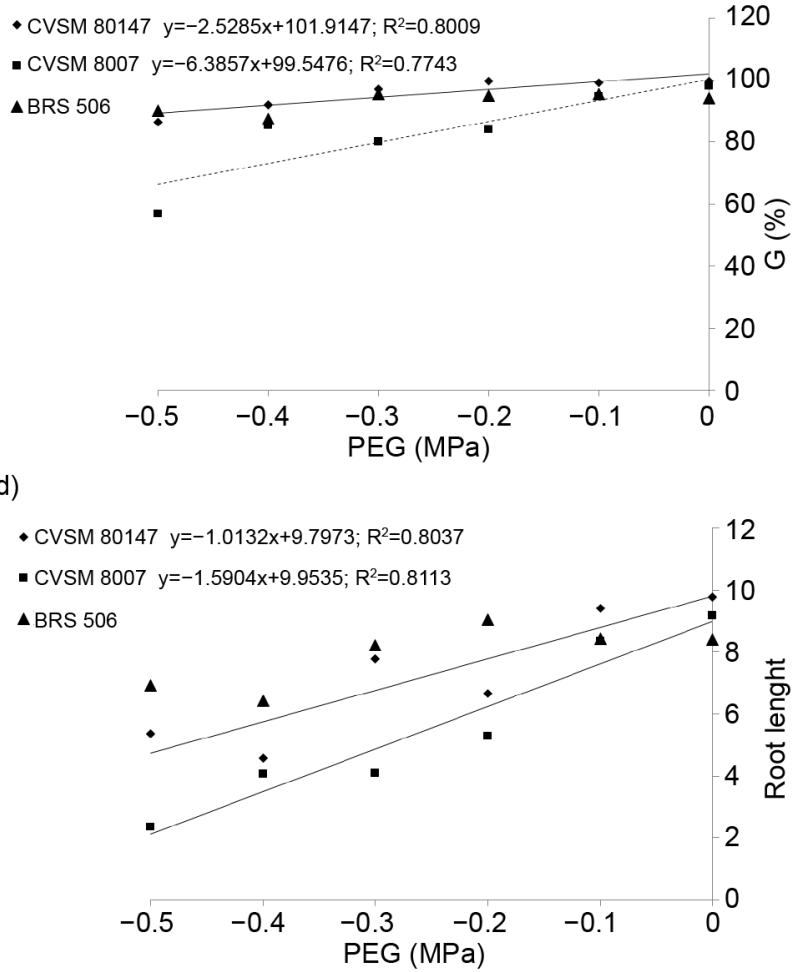

(f)



Figure 2. (a) Germination first count (\%), (b) Germination (\%), (c) Germination speed index (GSI), (d) Root length $\left(\mathrm{cm} \cdot\right.$ seedling $\left.^{-1}\right)$, (e) Root fresh weight $\left(\mathrm{g} \cdot\right.$ seedling $\left.^{-1}\right)$ and $(\mathrm{f})$ root dry weight $\left(\mathrm{g} \cdot\right.$ seedling $^{-1}$ ) from three seed lots of sweet sorghum submitted to substrates at different water potentials (MPa).

low water availability during the stages of crop growth, reducing the water potential of the substrate under controlled conditions during the early stages of germination has been reported to be harmful for seed germination of bioenergetic crops. Reference [22] who studied Jatropha seeds found that substrate moisture below 3.0 times the weight of the paper substrate caused a reduction in the percentage of germination and seed vigor. Reference [23], while evaluating the use of water restriction in sunflower seeds, found that below the potential of $-0.6 \mathrm{MPa}$, germination markedly decreased, especially in lots with less vigor. Reference [24] reported that for Crambe abyssica, regardless of the moisture content of the seeds, a significantly lower percentage 
of formation of normal seedlings was observed as the water availability of the substrate was reduced to a potential of $-0.4 \mathrm{MPa}$.

In terms of GSI, a significant interaction between genotypes and water potentials was established, and a linear model was observed with high regression adjustment, showing the deleterious effects of reduced water potential on the germination speed of seeds of all genotypes assessed, which was significantly slower (Figure 2(c)). The time of germination of sorghum seeds sensitive (CSF 18) and tolerant (CSF 20) to water deficit was directly proportional to the availability of water in the substrate [20]. These results can be explained by the higher water restriction that causes the extension of the stationary phase of the imbibition process due to a reduced enzymatic activity, which in turn leads to a slower rate development of the meristem, and hence, a delay in germination [19]. Reference [25], while studying the effect of water stress in 11 varieties of feed sorghum in a greenhouse, observed that the varieties with the fastest growth did not necessarily exhibit drought resistance behavior. This can be explained by competition, because plants with faster growth consequently have higher population density (i.e., the growth speed did not differentiate the behavior of varieties in relation to drought resistance).

For root growth, the effect of the water potential of a substrate was observed for hybrids CV 007 and CV 147 (Figure 2(d)), with a linear decrease in length as the water potential of the substrate also decreased. For cultivar BRS 506, no significant effects of the treatments on root length were observed, as shown by the common rustic characteristic of the material. However, the fresh and dry weights of the roots of the seedlings of cultivar BRS 506 were affected by the reduction in water potential, as shown by the linear decrease in fresh weight and increase in dry weight as the water potentials decreased (Figure 2(e) and Figure 2(f), respectively). A similar behavior was observed for the fresh weight of the two hybrids under study (Figure 2(e)) and in root dry weight of hybrid CV 147 (Figure 2(f)). Compared to hybrid CV 147, hybrid CV 007 was more sensitive to decreases in the water potential of the substrate. Reference [26] reported that the decrease in growth caused by reduced cell expansion is the first measurable effect of water stress. For root dry weight of hybrid CV 007, a quadratic equation fit was observed with maximum results $(0.2 \mathrm{~g})$ at $-0.22 \mathrm{MPa}$ water potential, with further decrease in potential from this concentration negatively affecting the transfer of reserves to the formation of seedlings.

The increase in root dry weight may be explained by an increased translocation of seed reserves to the root as the water stress increased with the concentrations of the aqueous solutions. Although the water restriction of the substrate was marked, the observed increase may be attributable to the stiffening of the walls of developing cells as the primary adjustment mechanism to reduced water availability for imbibition [24]. In this sense, the results in- 
dicate the rustic behavior of sorghum genotypes under PEG-simulated water stress.

Reference [27] studied the effect of water stress on the sweet sorghum cultivar Keller under field conditions with the aim of improving irrigation and found that under osmotic potential values close to $-0.4 \mathrm{MPa}$, the wilting point was achieved. The effect of water stress was higher in the early stage of the culture, when it reduced the biomass production by $30 \%$. The genotypes of sweet sorghum examined in this study were sensitive to reductions in water potentials during the early stages of germination and the results are relevant in assessing the conditions necessary for optimal growth of this crop.

Accordingly, the evaluation of the physiological potential of the seeds was efficient in detecting the deleterious effects of reduced water availability at a $-0.1 \mathrm{MPa}$ potential during the subsequent stages of germination and is in accordance with the results by [28], we suggested that the germination test under water stress at $-0.6 \mathrm{MPa}$ can be used to estimate the performance of sorghum seeds under unfavorable conditions of soil water availability.

\section{Conclusions}

Seeds germination and growth of seedlings of sorghum hybrids CV 007 and CV 147 and of the cultivar BRS 506 were affected by reductions in the water potential starting at $-0.1 \mathrm{MPa}$.

The seeds of hybrid CV 147 were more tolerant to water stress simulated using PEG 6000 than that by the seeds of the hybrid CV 007 and the cultivar BRS 506.

Through this study, it was possible to ratify the different responses that occur in the genotypes of sweet sorghum submitted to the osmotic stress that directly affected the seeds germination and the initial seedlings growth. These results serve as a basis for breeding programs that should seek to develop technologies that are resistant to the problems caused by the global climate change, thus meeting the demand for renewable energy production in different environments that are not always favorable to the cultivation of single sorghum sweet or applied to crop rotation systems.

\section{Acknowledgements}

To Federal University of Grande Dourados for research support.

\section{References}

[1] Lipinski, E.S. and Kresovich, S. (1982) Sugar Crops as a Solar Energy Converter. Experientia Supplementum, 38, 13-18. https://doi.org/10.1007/BF01944518 https://link.springer.com/chapter/10.1007/978-3-0348-6305-6_3

[2] Parrella, R.A.C. (2011) Genetic Improvement of Sorghum Saccharin. Agroenergia em Revista, 2, 8-9.

https://www.infoteca.cnptia.embrapa.br/infoteca/bitstream/doc/919537/1/BolfeAgr oeRevis.pdf 
[3] May, A. (2012) Embrapa System of Agroindustrial Production of Sorghums accharin for Bioethanol BRS1G System-Embrapa Quality Technology. Embrapa Milho e Sorgo, Sete Lagoas, 120 p. (Documents, 139) http://ainfo.cnptia.embrapa.br/digital/bitstream/item/72469/1/Doc-139-1.pdf

[4] Teixeira, C., Jardine, J.G. and Beisman, D.A. (1997) Sweet Sorghum Utilization as Complementary Raw Material of Sugar Cane for Ethanol Production in Microdistillery. Ciência Tecnologia de Alimentos, 17.

[5] Landau, E.C. and Schafertt, R.E. (2011) Areas Zoing Suitable for the Planting of Sorghum during Off-Season of Sugarcane in Brazil. Agroenergia em Revista, 2, 20-21.

https://www.infoteca.cnptia.embrapa.br/infoteca/bitstream/doc/901860/1/Zoneame ntoareas.pdf

[6] May, A., Albuquerque Filho, M.R., Landau, E.C., Parrela, R.A.C. and Massafera, R. (2011) Sorgum Cultivars for the Brazilian market in the 2011/2012 Crop. Embrapa Milho e Sorgo, Sete Lagoas, 28 p. (Documents, 117).

https://www.infoteca.cnptia.embrapa.br/infoteca/bitstream/doc/908224/1/doc117.p df

[7] Almodares, A. and Hadi, M.R. (2009) Production of Bioethanol from Sweet Sorghum: A Review. African Journal of Agricultural Research, 4, 772-780. http://www.academicjournals.org/journal/AJAR/article-full-text-pdf/6DDEDD7388 $\underline{26}$

[8] Miranda, M.R.S. (2011) Sorgum Bagasse: Kinetic Parameters and Analytical Pirolysis Estimates. Master's Degree Dissertation, Federal University of Uberlândia, Uberlândia.

[9] Marcos Filho, J. (2005) Seed Physiology of Cultivate Plants. FEALQ, Piracicaba.

[10] Wuest, S.B. (2007) Vapour Is the Principal Source of Water Imbibed by Seeds in Unsaturated Soils. Seed Science Research, 17, 3-9. https://doi.org/10.1017/S0960258507383165

[11] Bewley, J.D. and Black, M. (1994) Seeds: Physiology of Development and Germination. 2nd Edition, Plenum Press, New York. https://doi.org/10.1007/978-1-4899-1002-8

[12] BRASIL (Ministério da Agricultura, Pecuária e Abastecimento) (2009) Seed Analysis Rules. Ministério da Agricultura, Pecuária e Abastecimento, Secretaria de Defesa Agropecuária, Brasília.

[13] Michel, B.E. and Kaufmann, M.R. (1973) The Osmotic Potential of Polyethylene Glycol 6000. Plant Physiology, 51, 914-916. https://doi.org/10.1104/pp.51.5.914

[14] Maguire, J.D. (1962) Speed of Germination-Aid in Selection and Evaluation for Seedling Emergence and Vigor. Crop Science, Madison, 2, 176-177. https://doi.org/10.2135/cropsci1962.0011183X000200020033x

[15] Jones, B. (2013) EXCEL (Computer Program). Microsoft Corporation, Chicago.

[16] Ferreira, D.F. (2000) SISVAR (Analysis of Variance System). Federal University of Lavras (Exact Scienses Departament DEX), Lavras, CD-ROM.

[17] Pantenè, C., Cavallaro, V. and Cosentino, S.L. (2009) Germination and Radicle Growth in Unprimed and Primed Seeds of Sweet Sorghum as Affected by Reduced Water Potential in $\mathrm{NaCl}$ at Different Temperatures. Industrial Crops and Products, 30, 1-8. https://doi.org/10.1016/j.indcrop.2008.12.005

[18] Pantenè, C., Saita, A., Tubeileh, A., Cosentino, S.L. and Cavallaro, V. (2016) Modeling Seed Germination of Unprimed and Primed Seeds of Sweet Sorghum under 
PEG-Induced Water Stress through the Hydrotime Analysis. Acta Physiologiae Plantarumt, 38, 2-12.

[19] Silva, A.G., Rocha, V.S., Cruz, C.D., Sediyama, T. and Pinto, G.H.F. (2005) Adaptability and Stability of Sorghum Cultivars Sown at Different Times of the Year. Revista Brasileira de Milho e Sorgo, 4, 112-125.

https://ainfo.cnptia.embrapa.br/digital/bitstream/item/33893/1/Adaptabilidade-esta bilidade.pdf https://doi.org/10.18512/1980-6477/rbms.v4n1p112-125

[20] Oliveira, A.B. and Gomes-Filho, E. (2009) Germination and Vigor of Sorgum Seeds under Water and Salt Stress. Revista Brasileira de Sementes, 31, 48-56. https://doi.org/10.1590/S0101-31222009000300005

[21] Carvalho, L.F., Medeiros-Filho, S., Rossetti, A.G. and Teófilo, E.M. (2000) Osmo Condition in Sorghum Seeds. Revista Brasileira de Sementes, 22, 185-192. https://doi.org/10.17801/0101-3122/rbs.v22n1p185-192

[22] Silva, H.P., Neves, J.M.G., Brandão Junior, D.S. and Costa, C.A. (2008) Amount of Water in the Substratum on the Germination and Vigor of Seeds of Pinhão-Manso. Revista Caatinga, 21, 178-184.

[23] Barros, C.S. and Rossetto, C.A.V. (2009) Germination Test under Water Restriction to Evaluate Sunflower Seeds Vigor. Ciência Rural, Santa Maria, 39.

[24] Masetto, T.E., Quadros, J.B., Ribeiro, D.M., Rezende, R.K.S. and Scalon, S.P.Q. (2011) Effect of Substrate Water Availability and Seed Moisture Content on Crambe Germination. Revista Brasileira de Sementes, 33, 511-519. https://doi.org/10.1590/S0101-31222011000300014

[25] Amaral, S.R., Lira, M.A., Tabosa, J.N., Santos, M.V.F., Mello, A.C.L. and Santos, V.F. (2003) Forage Sorghum Lines Submitted to Water Déficit Stress under Controlled Conditions. Pesquisa Agropecuária Brasileira, 38, 973-979. https://doi.org/10.1590/S0100-204X2003000800010

[26] Taiz, L. and Zeiger, E. (2013) Vegetal Physiology. 5th Edition, Artmed, Porto Alegre.

[27] Mastrorilli, M., Katerji, N. and Rana, G. (1999) Productivity and Water Use Efficiency of Sweet Sorghum as Affected by Soil Water Deficit Occurring at Different Vegetative Growth Stages. European Journal of Agronomy, 11, 207-215. https://doi.org/10.1016/S1161-0301(99)00032-5

[28] Torres, S.B. (1997) Physiological Quality of Grain Sorghum Seeds by the Hydric Stress Test. Ciência Rural, Santa Maria, 27, 31-35. https://doi.org/10.1590/S0103-84781997000100006 